\title{
A CALIFASIA E A FORMAÇÃO DE PROFESSORES NA ESCOLA NORMAL DE SÃO PAULO
}

\author{
FREITAS, Anamaria Gonçalves Bueno de (Brasil, Sergipe, Aracaju) ${ }^{1^{*}}$ \\ ${ }^{1}$ Universidade Federal de Sergipe \\ https://orcid.org/0000-0003-1386-525X
}

\section{RESUMO}

No contexto da implantação da Escola Nova em São Paulo e de novas exigências para a formação dos professores, Francisco Silveira Bueno (18981989) foi aprovado em concurso em 1929 na Escola Normal para ministrar aulas de Português e Califasia. A preocupação com a arte da dicção expressiva na interpretação de textos fez com que - professor se dedicasse à produção de um manual específico para o ensino da Califasia. $O$ objetivo deste estudo é analisar a legislação do período e o manual a fim de compreender as contribuições do autor e da disciplina para os futuros professores. A pesquisa fundamenta-se nos pressupostos teóricos e metodológicos da história cultural e dialoga com a produção da história das disciplinas escolares. Aborda as questões relacionadas com a autoria didática, representações e apropriações de conteúdos e saberes para o exercício do magistério no contexto das primeiras décadas do século XX. PALAVRAS-CHAVE: Currículo. Formação de professores. História da educação.

\section{ABSTRACT}

In context of implementing the "Escola Nova" in São Paulo and the new demands for the professors' training, Francisco Silveira Bueno (1898-1989) was approved in a contest for selecting professors at "Escola Normal", in 1929, to teach Portuguese and Califasia. The concern with the art of expressive diction in interpretation of texts caused the professor to dedicate himself to the production of a specific manual for teaching Califasia. The goal of this study is to analyse the legislation for the period and the manual in order to comprehend the contributions of the author and the discipline for future professors. The research is based on presumed theory and on cultural history, and is related to the production of the history of school subjects. It addresses issues related to the educationalist, representations and appropriations of contents and knowledge to exercise teaching in the context of the first decades of the twentieth century.

KEYWORDS: Curriculum. Professors training. History of education.

\section{LA CALIFASIA Y LA FORMACIÓN DE PROFESORES EN LA ESCUELA NORMAL DE SÃO PAULO}

\section{RESUMEN}

En el contexto de la implantación de la Escuela Nueva en São Paulo y de los nuevos requisitos para la formación de los profesores, Francisco Silveira Bueno (1898-1989) fue aprobado en concurso en 1929 en la Escuela Normal para dar clases de Portugués y Califasia. La preocupación con el arte de la dicción expresiva en la interpretación de textos hizo que el profesor se dedicara a la producción de un manual específico para la enseñanza de la Califasia. El objetivo de este estudio es analizar la legislación del período y el manual a fin de comprender las contribuciones del autor y de la asignatura para los futuros profesores. La investigación se fundamenta en los presupuestos teóricos y metodológicos de la historia cultural y dialoga con la producción de la historia de las asignaturas escolares. Aborda las cuestiones relacionadas con la autoría didáctica, representaciones y apropiaciones de contenidos y saberes para el ejercicio del magisterio en el contexto de las primeras décadas del siglo XX.

PALABRAS CLAVE: Currículum. Formación de profesores. Historia de la educación. 


\section{INTRODUÇÃO}

A intenção deste estudo é analisar a introdução e retirada de uma disciplina do currículo da formação docente, na Escola Normal de São Paulo, na perspectiva da pedagogia científica e da racionalização didática, nas primeiras décadas do século $X X$. As fontes principais utilizadas na investigação foram: a legislação, os registros na imprensa, as memórias e o manual produzido por Francisco Silveira Bueno (1898-1989) para ministrar a cadeira de Califasia - que pode ser compreendida como a arte da dicção expressiva na interpretação de textos -, que recebeu diferentes edições.

A pesquisa encontra-se fundamentada nos pressupostos teóricos e metodológicos da história cultural e dialoga com a produção da história das disciplinas escolares e da história da profissão docente. Aborda as questões relacionadas com: as disputas no campo educacional e do currículo, a autoria didática, além das representações e apropriações de conteúdos e saberes para o exercício do magistério.

Nas alterações curriculares previstas em diversos estados pelas reformas estaduais nas primeiras décadas da República, não só para o ensino primário, mas também para a formação docente, pode-se identificar diferentes prescrições, práticas e apropriações para que os futuros docentes conseguissem atender aos dispositivos da modernidade pedagógica proposta pela retórica republicana.

As tensões entre tradição e modernidade no campo educacional podem ser observadas no cenário nacional não apenas no início da República, no entanto, neste contexto específico, a intensa circulação de manuais didáticos, revistas e jornais de cunho pedagógico, bem como inquéritos realizados pela grande imprensa, permitem que os conflitos sejam evidenciados com cores mais fortes e com a legitimação de grupos e agremiações, como é o caso da Associação Brasileira de Educação, criada em 1924 no Rio de Janeiro.

Marta Carvalho (1989, p. 9) ressaltou como o processo educativo foi valorizado nesse período:

[...] o papel da educação foi hiperdimensionado: tratava-se de dar forma ao país amorfo, de transformar os habitantes em povo, de vitalizar o organismo social, de construir a nação. Nele se forjava o projeto político autoritário: educar era a obra de moldagem de um povo, matéria informe e plasmável, conforme os anseios de Ordem e Progresso de um grupo que se autoinvestia como elite com autoridade para promovê-los.

Educação \& Formação, Fortaleza, v. 4, n. 10, p. 81-94, jan./abr. 2019

DOI: https://doi.org/10.25053/redufor.v4i10.520

http://seer.uece.br/redufor 
A supervalorização do papel social da escola, de difusão dos ideais escolanovistas, de importação de materiais didáticos de países europeus e dos Estados Unidos, os debates e as propostas acerca da formação docente no Brasil foram visibilizados pela imprensa de forma recorrente. A preocupação em conciliar nos currículos, entre outros aspectos, os conhecimentos específicos de cada área de conhecimento com elementos da pedagogia ativa; a cultura geral exigida dos novos professores e professoras; e a gradação e/ou hierarquia da formação (em muitos casos: cursos complementares, escolas normais primárias, escolas normais secundárias e cursos de aperfeiçoamento) estiveram presentes em diferentes legislações e regulamentos das Escolas Normais do país.

Como elementos comuns, identificaram-se a construção e a inauguração de prédios monumentais em locais de destaque para abrigar as instituições formadoras, baseados nos princípios dos higienistas, principalmente nas capitais dos estados, mas as exigências de ingresso (idade mínima e máxima, exames de admissão, exames de saúde), os anos de estudo para a conquista do diploma de normalista e a composição curricular foram muito diversificados, aspectos fundamentados em prescrições legais alteradas com muita frequência.

Como nos advertiram Valdemarin e Rocha (2015, p. 348), compreende-se que:

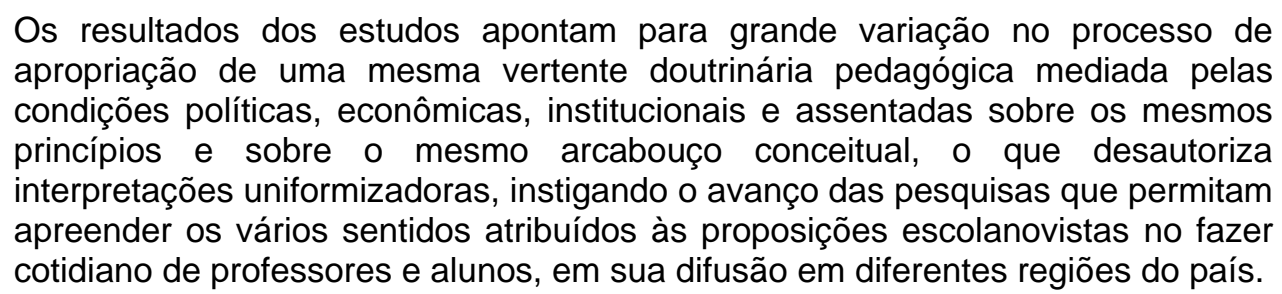

O recorte desta investigação procurou observar a presença de uma disciplina, a Califasia, geralmente associada ao ensino de língua portuguesa e/ou vernáculo, e a publicação de um manual para a referida disciplina pelo professor Francisco Silveira Bueno. Até o momento, no estudo realizado em outros currículos de formação (ARAÚJO; FREITAS; LOPES, 2008), não se identificou outra Escola Normal que tivesse a prescrição de ministrar a referida disciplina, ou mesmo os conteúdos previstos, nas primeiras décadas do século XX, apenas a Escola Normal de São Paulo.

Bontempi Júnior (2001, p. 5) indicou que, no caso das pesquisas sobre disciplinas (escolares e acadêmicas), há necessidade de analisar as disputas e tensões: 
[...] não é possível investigar a história de qualquer disciplina sem a realização concomitantemente de um esforço para 'desnaturalizar' o objeto, devolvendo-lhe sua condição histórica de disciplina em constituição. Tomá-la, pois, como disciplina possível, ou seja, como resultado de lutas e negociações que teve de enfrentar, para sua consolidação, quer no ambiente acadêmico, quer no político, e não como um corpo solidificado de temas, doutrinas, modos e hierarquias de que não se questiona o porquê, como e quando.

No sentido de contribuir com os questionamentos propostos por Bontempi Júnior (2001), o currículo é compreendido nesta investigação, segundo Ivor Goodson (1997, p. 17), como "[...] um artefato social, concebido para realizar determinados objetivos humanos específicos". Assim, as prescrições curriculares, estabelecidas em dispositivos diversos, como alerta Goodson (1997, p. 18), "[...] como plano de estudos, orientações programáticas e manuais das disciplinas", possuem:

[...] significado simbólico, mas também um significado prático. Simbólico, porque determinadas intenções educativas são, deste modo, publicamente comunicadas e legitimadas. Prático, porque estas convenções escritas traduzem-se em distribuição de recursos e em benefícios do ponto de vista da carreira. (GOODSON, 1997, p. 20).

O ensino de Califasia foi localizado como disciplina do curso complementar existente na Escola Normal de São Paulo, com 11 aulas semanais (Lei n. 1.750, de 8 de dezembro de 1920), e desapareceu do currículo ministrado na Escola Normal de São Paulo com a publicação do Código da Educação (Decreto n. 5.884, de 21 de abril de 1933), que reformou o ensino paulista nos seus diferentes níveis, alterou disciplinas e deu nova configuração à instituição, passando a ser denominada de Instituto de Educação "Caetano de Campos". Essa instituição passou a ser composta por: Escola de Professores (com cursos para: professores primários; secundários; diretores e inspetores escolares); Escola Secundária; Escola Primária e Jardim de Infância, em nenhum deles a disciplina de Califasia figurou no currículo prescrito.

\section{AS LIÇÕES DE PORTUGUÊS E CALIFASIA NA ESCOLA NORMAL DE SÃO PAULO}

A Escola Normal de São Paulo foi criada em 1846 e passou por diversos atos de fechamento e recriação, como as outras instituições congêneres no Brasil. Assim, como atestou Tanuri (1979), a referida instituição encerrou as atividades em 1867, reabriu em

Educação \& Formação, Fortaleza, v. 4, n. 10, p. 81-94, jan./abr. 2019

DOI: https://doi.org/10.25053/redufor.v4i10.520

http://seer.uece.br/redufor 
1876, após um ano de funcionamento, fechou novamente em 1877, voltando às atividades em 1880.

No caso de São Paulo, como em outros estados, o processo de consolidação da formação docente nas Escolas Normais aconteceu de modo mais constante a partir das últimas décadas do final do século XIX e início do século XX. No entanto, foi com a Lei Orgânica do Ensino Normal (Decreto-Lei n. 8.530, de 2 de janeiro de 1946) que a determinação nacional dos currículos, da duração dos cursos e das modalidades permitidas passou a ser unificada, padronizando, desse modo, os processos de formação nos cursos normais.

A busca por uma relação consistente entre os estudos teóricos e os exercícios práticos, ou mesmo entre disciplinas científicas e metodológicas, ocupa o cenário das reformas educacionais na formação docente principalmente na passagem do século XIX para o XX nas diferentes regiões do país. No caso paulista, Tanuri (2000, p. 69) destacou:

\begin{abstract}
Digna de nota nesses primeiros anos foi, de um lado, a influência das filosofias cientificistas, consubstanciada sobretudo no papel disciplinar, metodológico atribuído às ciências e na importância que elas passaram a ganhar nos currículos. De outro, a introdução dos primeiros ensaios de renovação pedagógica no ensino público, ressaltando-se o valor da observação, da experiência sensorial, da educação dos sentidos, das 'lições de coisas', do método intuitivo de Pestalozzi. Assim, a reforma paulista realizada já a 12/03/1890, sob a direção de Caetano de Campos, ampliou a parte propedêutica do currículo da escola normal e contemplou as suas escolas-modelo anexas, bem como a prática de ensino que os alunos aí deveriam realizar.
\end{abstract}

O Decreto n. 3.858, de 11 de junho de 1925, rezava que o ensino de Califasia, associado ao ensino de Português, deveria existir não apenas na Escola Normal da capital, mas também em outras Escolas Normais no interior do estado de São Paulo. O curso normal, previsto com cinco anos de duração, teria três aulas semanais da disciplina nos primeiros dois anos. O ensino de música foi prescrito para os cinco anos de formação, com duas aulas semanais, além da constituição de um orfeão escolar:

Artigo 46 - São materias do programma: portuguez e calliphasia, litteratura e historia da lingua; francez, inglez, latim; geographia da America e do Brasil; cosmographia e geographia geral; historia da civilisação, da America e do Brasil especialmente: arithmetica, algebra e geometria; physica, chimica, anatomia e physiologia humanas, biologia, hygiene e noções de puericultura; psychologia, pedagogia, didactica; noções de direito usual; desenho; trabalhos manuaes; musica; gymnastica. Artigo 47 - Em cada escola normal haverá, sob a regencia do professor de musica respectivo, um Orpheon Escolar. $\S 1.0-$ O Orpheon Escolar terá por fim sustentar e divulgar a musica nacional, despertar e cultivar 0

Educação \& Formação, Fortaleza, v. 4, n. 10, p. 81-94, jan./abr. 2019

DOI: https://doi.org/10.25053/redufor.v4i10.520

http://seer.uece.br/redufor 
sentimento patriotico e o gosto esthetico da mocidade brasileira. $\S 2 . .-$ - A escolha das letras e das musicas deve recahir sobre producções de autores nacionaes. § 3.․ - Com excepção dos hymnos das outras nações, não será permittida no Orpheon Escolar letra em outro idioma que não seja o nacional. (SÃO PAULO, 1925, grifos nossos, manteve-se a grafia original).

Ressalta-se que a existência do ensino de música e canto nas escolas paulistas (principalmente nas escolas primárias e normais) era prevista desde o século XIX, no entanto, nas regulamentações dos cursos normais nas primeiras décadas do século XX, em São Paulo, identifica-se a exigência da formação do orfeão escolar para o incentivo do aprendizado das canções nacionais desde a Lei n. 1.750, de 8 de dezembro de 1920. O ensino de Português e Califasia, na Lei n. 2.269, de 31 de dezembro de 1927, determinava que o mesmo deveria ocorrer tanto na formação oferecida pelas Escolas Normais, com duração de três anos, como nos cursos complementares, contudo a referida lei não indicou normas específicas para o orfeão escolar.

Francisco Silveira Bueno nasceu em 20 de agosto de 1898, em Jarinu, comarca de Atibaia, no interior de São Paulo (SP), e faleceu na capital do estado em 2 de agosto de 1989. Filho de Alexandrino Silveira Bueno (1853-1919) e Antonia Maria do Nascimento (1856-1951), ambos professores primários em Jarinu. Francisco foi o último filho do casal e possuía 10 irmãos ao nascer.

Iniciou seus estudos primários no Grupo Escolar "José Alvim”, em Atibaia (SP), e concluiu no Grupo Escolar "Coronel Leme", em Leme (SP), onde seu irmão mais velho, José Pedro da Silveira, era diretor. Foi matriculado no Seminário Menor de Pirapora, de onde foi transferido para o Seminário Provincial de São Paulo após cinco anos, nesse tempo, Faculdade de Filosofia e Teologia agregada à Universidade Gregoriana de Roma. Em 1917, defendeu a tese que Ihe valeu a conclusão do curso, permanecendo mais quatro anos na instituição para se dedicar à formação em Teologia, Direito Canônico e Exegese Bíblica. Estudou grego e hebraico durante esse processo.

Depois de abandonar a carreira eclesiástica, realizou o curso de Filosofia na Faculdade de Filosofia São Bento e dedicou-se ao magistério e ao jornalismo. Ensinou Latim, Português e História no Mackenzie College, no Colégio São Bento, no Colégio São Luís, no Colégio Pan-Americano e no Colégio Paulistano, concorrendo em 1929 à cátedra de Português e Califasia na Escola Normal de São Paulo, tendo sido classificado em primeiro lugar e sendo nomeado no mesmo ano. 
Em 1939, prestou concurso para a cátedra de Filologia Portuguesa da Faculdade de Filosofia Ciências e Letras da Universidade de São Paulo, sendo aprovado. Colaborou em jornais de São Paulo e do Rio de Janeiro durante muitas décadas. Participou da redação dos seguintes jornais: Jornal do Comércio, Folha da Manhã, Folha da Noite, Platéia, Diário Paulista e A Tarde.

Professor, crítico, ensaísta, poeta, conferencista e tradutor, especializou-se nas décadas de quarenta e de cinquenta do século $X X$ em pesquisas sobre Filologia e Linguística. Fez conferências na Espanha a convite do Instituto de Alta Cultura Hispânica e da Academia de Língua Espanhola, assim como em Coimbra e em Lisboa. Usou o pseudônimo de Frei Francisco da Simplicidade em diversos momentos de sua trajetória como escritor.

Em seu livro de memórias, intitulado Na tormenta da vida: memórias de um batalhador, publicado postumamente, em 1996, Silveira Bueno registrou que foi convidado em 1930 por Joaquim Inácio da Fonseca Saraiva para produzir livros didáticos de Língua Portuguesa para o ensino ginasial. Nas décadas seguintes, Silveira Bueno também foi autor, pela mesma editora, de diversas obras de diferentes estilos: livros didáticos para o ensino normal e superior, gramáticas, livros de viagens, romances, uma revista especializada, dicionários, entre outros.

O concurso realizado na Escola Normal da capital para a cadeira de Português e Califasia começou no dia 26 de julho de 1929 e o resultado final foi divulgado publicamente no dia 9 de agosto do mesmo ano. Inscreveram-se os professores: Maria Antonia de Mello, José Rizzo, Francisco da Silveira Bueno, Francisco Oscar Penteado Stevenson, Coriolano Moraes Monteiro, Francisco de Assis Gonzaga de Moraes e Padre José Marcellino Nunes de Araújo. Na prova escrita realizada no dia 26 de julho de 1929, às 8:00 horas da manhã, no anfiteatro do Jardim de Infância, alguns candidatos deixaram de comparecer, perdendo o direito de continuar participando do processo. A banca examinadora foi constituída por: professor Honorato Faustino de Oliveira (presidente), doutor Américo de Moura, professor Jairo Bueno de Camargo, professor Erasto Toledo (examinadores) e professor Antonio de Firmino Proença (delegado do governo) (SÃO PAULO, 1937). Não compareceram os seguintes concorrentes: Coriolano Moraes Monteiro, Francisco de Assis Gonzaga de Moraes e Padre José Marcellino Nunes de Araújo (SÃO PAULO, 1937). 
De acordo com as atas do referido concurso, a prova escrita tinha duração de quatro horas, sendo ministradas duas aulas por candidato às turmas da Escola Normal, com pontos sorteados, uma aula versando sobre Língua Portuguesa e a outra sobre Califasia. Antes das aulas, acontecia a prova de preleção com sorteio do ponto, com 24 horas de antecedência, cada candidato deveria tratar do ponto sorteado pelo período de uma hora. Após a leitura pública da prova escrita, cada examinador apresentava publicamente a sua nota para cada um dos candidatos, sendo o resultado então divulgado. $O$ debate entre os candidatos era previsto em regimentos de concurso para as Escolas Normais desde o século XIX.

As diferentes etapas que constituíam o concurso foram descritas por Silveira Bueno no seu livro de memórias. O autor fez questão de ressaltar sua posição diante dos concorrentes e as estratégias que usou:

\begin{abstract}
O regimento deste concurso era o mais curioso de todos, pois, além da prova escrita, as orais deveriam desenvolver-se entre os candidatos e não entre estes e a banca examinadora. Éramos divididos em grupos de dois e, sorteado o ponto de discussão, tínhamos doze horas para prepará-lo. Cada um dispunha de meia hora para argüir o adversário, o que transformava a prova oral em verdadeira rinha de galos, com questões de algibeira. A banca examinadora ficava, de palanque, acompanhando os debates. Tais provas eram à noite e numeroso público acorria para assistir ao 'pega', pois não há assunto mais apaixonante do que as gramatiquices. Formavam-se, desta maneira, grupos de 'torcedores' a favor deste candidato ou de outro. Terminados os debates, havia ainda mais duas provas: uma dissertação de cinqüenta minutos e finalmente a aula este regimento vinha favorecer-me grandemente, pois, fosse o assunto da discussão, levava eu o adversário ao terreno histórico do nosso idioma e aí, latim ou grego, os estudos clássicos de que dispunha sobrevaleciam à ignorância geral dos concorrentes. A prova escrita não era objeto de discussão: no término de tudo, cada candidato lia a sua prova, fiscalizada por outro concorrente, e a banca examinadora dava a nota final apenas pela audição da leitura. (BUENO, 1996, p. 184, grifo nosso, manteve-se a grafia original).
\end{abstract}

Na prova de preleção de Maria Antonia de Mello, ocorrida no dia 2 de agosto de 1929, a professora foi desclassificada pelos examinadores, que registraram em ata que ela teria descumprido o regimento por não tratar unicamente do ponto sorteado no período estabelecido (SÃO PAULO, 1937). Assim, apenas três candidatos permaneceram participando do referido concurso: Francisco Silveira Bueno, Francisco Oscar Penteado Stevenson e José de Souza. No dia 9 de agosto de 1929, a classificação final dos candidatos foi: "[...] em 1ำ logar o Sr. Francisco Silveira Bueno com 184 pontos e a média 9,2; em 2o logar o Sr. Francisco Oscar Penteado Stevenson com 
167 pontos e a média 8,35 e em 3ํlogar o Sr. José de Souza com 158 pontos e a média 7,9" (SÃO PAULO, 1937, p. 188, manteve-se a grafia original).

No dia 16 de setembro de 1929, assinou o termo de compromisso, no gabinete do diretor da Escola Normal da capital, para exercer o cargo de lente da cadeira de Português e Califasia na Escola Normal, segundo o decreto de nomeação do dia 12 de setembro do mesmo ano (SÃO PAULO, 1930). Sobre esse dia, Silveira Bueno (1996, p. 188 , grifo nosso, manteve-se a grafia original) identificou as mudanças na sua vida pessoal que essa conquista permitiu:

\begin{abstract}
Com a consecução da cátedra, firma-se a minha modesta vida. Ficava livre do trabalho exaustivo e mal remunerado da vida jornalística, passando apenas a colaborador. Punha-me a salvo também que sempre reputei uma odiosidade: as aulas a alunos particulares. O dia da minha posse marcou data especial no meu calendário íntimo. Todos os professores sob a direção do Prof. Honorato Faustino de Oliveira receberam-me com grandes manifestações de amizade, encontrando entre os novos colegas pessoas de muita qualificação no magistério paulista.
\end{abstract}

A primeira edição do Manual de Calliphasia e Arte de Dizer foi disponibilizada, em 1930, pela São Paulo editora. A segunda edição foi publicada pela Livraria Acadêmica e Editora Saraiva \& Cia, ainda sob o mesmo título, e circulou no ano de 1939. Em 1951, a obra recebeu um novo título, que se fez presente nas edições subsequentes: Manual de Califasia, Califonia, Calirritmia e Arte de Dizer. A editora Saraiva foi responsável pelas outras edições, respectivamente: a quinta (1958), a sexta (1964) e a sétima (1966); até o presente, estas foram as edições encontradas. Os exemplares analisados neste estudo são da primeira e da quinta edições. É considerado o primeiro manual em português sobre o assunto, sendo posteriormente utilizado em diferentes disciplinas (como Canto Orfeônico) e cursos de formação de diferentes áreas, inclusive de Fonoaudiologia.

No prefácio da primeira edição do Manual de Calliphasia e Arte de Dizer (1930), Silveira Bueno indicou ser a sua iniciativa em reunir as lições que ministrava na Escola Normal da Praça, na cadeira de Califasia e Língua Portuguesa, em forma de compêndio para o uso em outras Escolas Normais. Além de se propor a "[...] offerecer um plano fácil de ensino aos professores", esperava que pudesse contribuir para que o estudo da matéria "[...] fosse desenvolvido methodicamente" (BUENO, 1930, p. 5, manteve-se a grafia original). O autor ressaltou que a "Califasia" e a "Arte de Dizer" são distintas, mas 
defendeu que a primeira era base indispensável da segunda e que esta "[...] surge como côroa e aperfeiçoamento daquela" (BUENO, 1930, p. 5, manteve-se a grafia original).

Estruturada em 12 capítulos, com 188 páginas, a primeira edição da obra versou sobre as seguintes temáticas: conceito de Califasia e suas utilidades; bases da Califasia e aparelho fonador; respiração; defeitos da voz (origem e tratamento); vogal e consoante; articulação; pronunciação; encadeamento; leitura em voz alta; palavras de valor; cadência; intensidade do movimento; colorido na diç̧ão; leitura dos versos; gestos; leitura simples e fisionomia; qualidades dos gestos, entre outras.

Com a extinção do ensino de Califasia associado ao ensino de Língua Portuguesa no ensino normal em São Paulo pelo Código de Educação de 1933 (Decreto n. 5.884, de 21 de abril de 1933), conforme afirmou-se anteriormente, Silveira Bueno assumiu a cadeira de Português e Literatura na Escola Secundária, que funcionava no mesmo prédio do Instituto de Educação Caetano de Campos, até realizar o concurso, em 1939, para a Faculdade de Filosofia Ciências e Letras da Universidade de São Paulo.

Na quinta edição do Manual de Califasia, Califonia, Calirritmia e Arte de Dizer, Silveira Bueno (1958, p. 5, manteve-se a grafia original) esclareceu no prefácio algumas das alterações da obra original, segundo ele, realizadas para atender às solicitações de professores e alunos de Canto Orfeônico:

\begin{abstract}
Aparece a quinta edição deste Manual de Califasia completamente modificada, segundo as exigências do ensino secundário. Nada menos do que quatro capítulos foram acrescentados, com muitos acréscimos aos já existentes em outras edições. A pedido de professores e alunos de canto orfeônico, tratamos de novos assuntos denominados: califonia e calirritmia. É necessário declarar que estes dois capítulos foram expostos sob o prisma da dicção aliada ao canto. [...] Colocamo-nos sempre em nosso campo lingüístico, deixando o terreno da música aos ilustres artistas do som.
\end{abstract}

A ampliação dos assuntos tratados por Silveira Bueno nessa quinta edição foi mantida em edições subsequentes. Dividida em 16 capítulos, com 237 páginas, a obra passou a despertar o interesse de um público mais amplo, não apenas os(as) alunos(as) das Escolas Normais. Na primeira edição, o Manual aparece indicado para o "[...] uso das escolas normaes e cursos de declamação" (1930). Na quinta edição, a referência foi feita "[...] para o uso das escolas normais, ginásios oficiais, canto orfeônico e declamação" (1958).

Educação \& Formação, Fortaleza, v. 4, n. 10, p. 81-94, jan./abr. 2019 
Aparentemente essa pequena alteração na indicação do público leitor, entre a primeira e a quinta edições, pode parecer irrelevante, entretanto a referida obra continuou a ser reeditada ao longo da década de 1960. Na "orelha" dessa quinta edição, uma advertência do comentador da obra, sobre a utilidade do Manual para diversos profissionais, permitiu - pelo menos do ponto de vista propositivo pela editora - uma certa ampliação do público leitor da mesma:

\begin{abstract}
Trata-se de obra de extrema utilidade e que interessa a todas as pessoas indistintamente. É, no entanto, de inestimável valor para quem está em permanente contato com o público e assim necessite de ser bem entendido e compreendido por ele. Oradores, políticos, artistas da declamação e do canto, técnicos de relações públicas, entre tantos outros, não podem dispensar os ensinamentos do Professor Silveira Bueno, expostos nesta obra de tanta utilidade intelectual, moral, pedagógica, social e estética. (BUENO, 1958, primeira orelha, manteve-se a grafia original).
\end{abstract}

Pensado inicialmente qual seria a melhor forma de ensinar Califasia para os futuros professores e declamadores, o referido Manual passou a ser, ao longo das décadas e das reedições, também uma ferramenta de orientações para os diferentes "profissionais da palavra". Silveira Bueno "traduziu" orientações e disposições necessárias aos variados tipos de oradores e também cantores, para que, com base na Califasia, Califonia e Calirritmia, pudessem exercer melhor suas distintas atividades.

Os exercícios de declamação e as práticas relacionadas ao Canto Orfeônico nas escolas brasileiras, relacionados com a difusão de valores cívicos e patrióticos, ganharam novos contornos no período Vargas, principalmente no Estado Novo. O orfeão escolar tornou-se obrigatório nacionalmente a partir de 1930, associado ao projeto político de formação do Estado Nacional, fomentado por Getúlio Vargas (SOUZA, 2009).

Mesmo não existindo mais a disciplina de Califasia na formação docente, foi possível identificar como Silveira Bueno foi adaptando os usos do Manual com objetivos diversos da primeira edição, mantendo-se no mercado editorial. Como ressaltou Catani (2008, p. 317):

[...] os impressos produzidos por professores (especialmente revistas, manuais pedagógicos e obras memorialísticas) têm nos últimos anos permitido conhecer aspectos centrais dos processos de formação/trabalho docente, especificidades do funcionamento deste espaço profissional e formas de circulação de modelos e conhecimentos pedagógicos.

Educação \& Formação, Fortaleza, v. 4, n. 10, p. 81-94, jan./abr. 2019 
Assim, percebe-se que, na perspectiva da legislação e da ação docente de Silveira Bueno, apreender e utilizar os recursos técnicos e didáticos da Califasia, da Califonia e da Calirritmia contribuía na formação docente, construída nas primeiras décadas do século $X X$, associados aos pressupostos da aquisição de erudição e de metodologias específicas para o ensino ativo.

\section{CONSIDERAÇÕES FINAIS}

Além das publicações didáticas para o ensino ginasial, normal e superior, na primeira metade do século $X X$, Silveira Bueno teve um programa de rádio, intitulado "Questões de Português" (década de 1930), em que respondia dúvidas de ouvintes ou enviadas por cartas. Algumas respostas foram reproduzidas na coluna "Questões de Português", que ele manteve na Folha da Manhã, e depois foram publicadas em livro (em dois volumes) com o mesmo nome em 1938, também recebendo diversas edições.

De acordo com o estudo realizado, foi possível perceber que Francisco Silveira Bueno soube associar docência e produção didática em todos os níveis de ensino em que atuou, tendo desenvolvido estratégias diversas para essas duas ações. Ressalta-se também que a Livraria Acadêmica e a Saraiva Editores, por muitas décadas, mantiveram um sistema de distribuição muito bem elaborado, com representantes em diferentes capitais do país, que favorecia a divulgação da sua produção didática e literária em diversos estados, entre eles: Rio de Janeiro, Minas Gerais, Pernambuco, Bahia, Paraná e Rio Grande do Sul.

Em 1962, Silveira Bueno foi homenageado pelo Instituto de Educação Caetano de Campos por completar 40 anos de magistério; neste mesmo ano, no dia 10 de maio, recebeu da Câmara Municipal de São Paulo o título de cidadão paulistano (SÃO PAULO, 1962). Em 1968, o referido professor foi aposentado compulsoriamente pela Faculdade de Filosofia, Ciências e Letras, na Universidade de São Paulo, mas continuou orientando trabalhos de mestrado e doutorado, vindo a falecer em 1989.

$\mathrm{Na}$ busca pela compreensão de aspectos da trajetória da disciplina de Língua Portuguesa e Califasia na Escola Normal da Praça da República, nas primeiras décadas do século XX, e da análise das contribuições de Francisco Silveira Bueno nesse campo, espero ter contribuído para elucidar elementos que possam favorecer novas 
investigações acerca da relação entre docência e autoria didática, problemática que me parece fértil para a história da profissão docente e a história das disciplinas escolares.

\section{REFERÊNCIAS}

ARAÚJO, J. C. S.; FREITAS, A. G. B.; LOPES, A. P. C. As Escolas Normais no Brasil: do Império à República. Campinas: Alínea, 2008.

BONTEMPI JÚNIOR, B. A cadeira de História e Filosofia da Educação da USP entre os anos de 40 e 60: um estudo das relações entre a vida acadêmica e a grande imprensa. 2001. Tese (Doutorado em História e Filosofia da Educação) - Programa de Pós-Graduação em História e Filosofia da Educação, Pontifícia Universidade Católica de São Paulo, São Paulo, 2001.

BUENO, F. S. Manual de Califasia e Arte de Dizer: para uso das Escolas Normais e cursos de declamação. 2. ed. São Paulo: Livraria Acadêmica: Saraiva \& Cia, 1939.

BUENO, F. S. Manual de Califasia, Califonia, Calirritmia e Arte de Dizer. 5. ed. São Paulo: Saraiva, 1958.

BUENO, F. S. Manual de Calliphasia e Arte de Dizer. São Paulo: São Paulo, 1930.

BUENO, F. S. Na tormenta da vida: memórias de um batalhador. São Paulo: Lisa, 1996.

BUENO, F. S. Questões de Português. São Paulo: Livraria Acadêmica: Saraiva \& Cia, 1938.

CARVALHO, M. M. C. A escola e a república. São Paulo: Brasiliense, 1989.

CATANI, D. B. Os escritos dos professores no campo educacional brasileiro (18901970). In: CONGRESSO LUSO-BRASILEIRO DE HISTÓRIA DA EDUCAÇÃO, 7., 2008, Porto. Anais... Porto: Universidade do Porto, 2008.

GOODSON, I. A construção social do currículo. Lisboa: Educa, 1997.

SÃO PAULO. 74a Sessão Especial, realizada em 10 de maio de 1962. Diário Oficial do Estado de São Paulo, Câmara Municipal de São Paulo, São Paulo. 13 maio 1962.

SÃO PAULO. Atas de Concurso (1894-1937). São Paulo: Instituto Caetano de Campos, 1937. SÃO PAULO. Decreto n. 3.858, de 11 de junho de 1925. São Paulo: Imprensa Oficial, 1925.

SÃO PAULO. Decreto n. 5.884, de 21 de abril de 1933. Código de Educação do Estado de São Paulo. São Paulo: Imprensa Oficial, 1933. 
SÃO PAULO. Lei n. 1.750, de 8 de dezembro de 1920. Reforma a Instrução Pública do Estado. São Paulo: Imprensa Oficial,1920.

SÃO PAULO. Lei n. 2.269, de 31 de dezembro de 1927. Reforma a Instrução Pública do Estado. São Paulo: Imprensa Oficial,1927.

SÃO PAULO. Livro de Compromisso (1921-1930). São Paulo: Instituto Caetano de Campos, 1930.

SOUZA, R. F. Alicerces da pátria: história da escola primária no estado de São Paulo (1890-1976). Campinas: Mercado de Letras, 2009.

TANURI, L. M. História da formação de professores. Revista Brasileira de Educação, São Paulo, n. 14, p. 61-88, 2000.

TANURI, L. M. O ensino normal em São Paulo. São Paulo: USP, 1979.

VALDEMARIN, V. T.; ROCHA, H. H. P. Métodos de ensino e renovação educacional na produção em História da Educação. In: SOUZA, R. F.; PINHEIRO, A. C. F.; LOPES, A. P. C. (Org.). História da educação primária no Brasil: investigação em perspectiva comparada em âmbito nacional. Aracaju: Edise, 2015. p. 331-358.

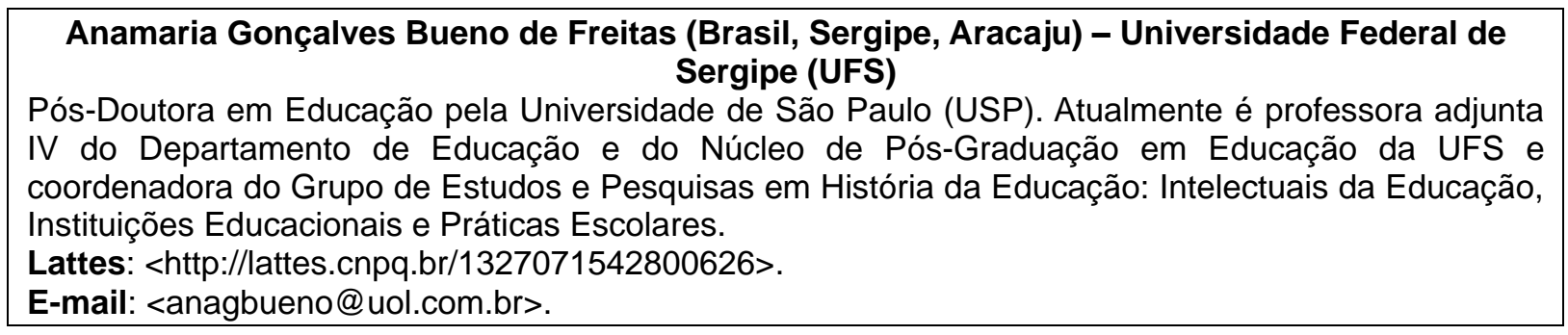

Recebido em 11 de outubro de 2018. Aceito em 9 de janeiro de 2019. 